
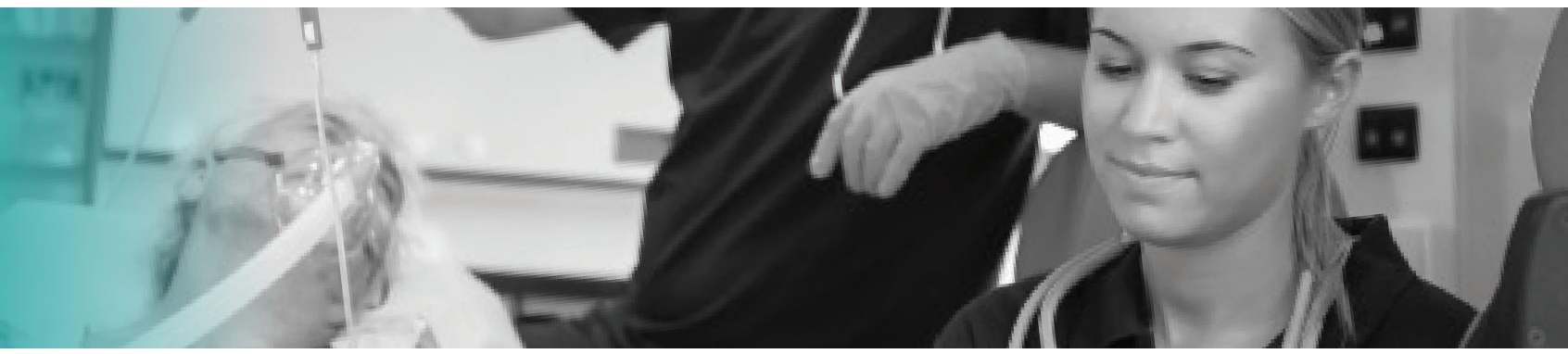

Volume 14 | Issue 3 | Article 2
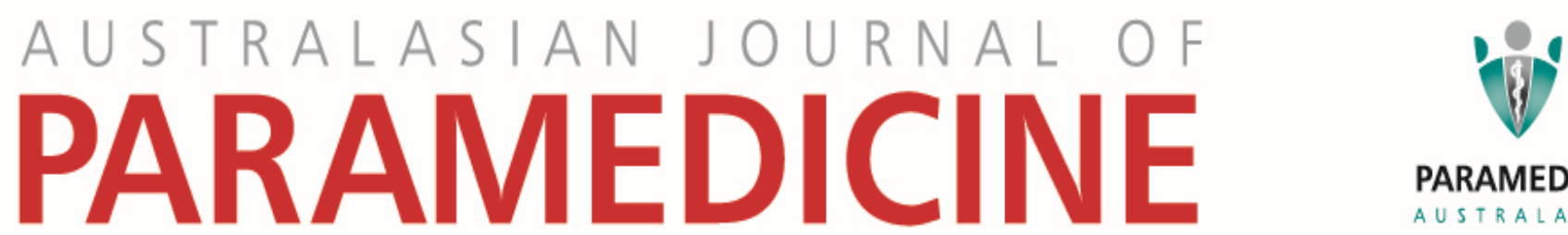

PARAMEDICS

AUSTRALASIA

\title{
Paramedic confidence in estimating external blood loss
}

\section{Wayne Harris}

University of Tasmania, Hobart

\section{Auston Rotheram}

University of Tasmania, Hobart

\section{Sue Pearson}

University of Tasmania, Hobart

\section{Peter V Lucas}

University of Tasmania, Hobart

\section{Dale Edwards}

University of Tasmania, Hobart

\section{Lisa Bowerman}

University of the Sunshine Coast, Queensland

\section{Anne-Marie Williams}

University of Tasmania, Hobart 


\title{
Research
}

\section{Paramedic confidence in estimating external blood loss}

Wayne Harris GradCertEd, BHlthSc(Paramedic), is Lecturer'; Auston Rotheram GradCertMgt, GradDipEmergHIth(MICA), Med, is Senior Lecturer ${ }^{1}$; Sue Pearson BA (HonsPsych), PhD, GradCert LT, is Lecturer ${ }^{1}$, Peter V Lucas BA, MSocSc, PhD, is Research Fellow'; Dale Edwards BHlthSc(Paramedic), GradCertEd, Med, is Senior Lecturer'; Lisa Bowerman MHlthSc (Ed) Grad Cert Emergency Services Education, Grad Cert Research; BHIthSc (Pre-hospital Care) is Senior Lecturer²; Anne-Marie Williams BSc, Grad Dip Exercise and Sport Science, PhD, Grad Cert University Learning and Teaching, Associate Professor Paramedic Leadership ${ }^{1}$

\author{
Affiliations: \\ ${ }^{1}$ University of Tasmania, Hobart \\ ${ }^{2}$ University of the Sunshine Coast, Queensland
}

\section{Abstract}

\section{Introduction}

Studies have identified that visual estimation of blood loss is highly inaccurate, however no research has investigated the relationship between this practice and the confidence of estimation by paramedics. The aim of this study was to determine paramedic confidence in the estimation of, and reporting of external blood loss due to medical or trauma aetiology, within an Australasian paramedic context.

\section{Methods}

Between July and September 2015, a cross-sectional survey was distributed through Australasian paramedic professional bodies to determine confidence in estimating and documentation of external blood loss. Using Likert scale and free text responses, participants provided demographic information and their self-perceived confidence in estimating and documenting external blood loss.

\section{Results}

Five thousand six hundred paramedics were invited to participate in an online survey. Two hundred and eight responses were received (3.8\% response rate). A total of $86.6 \%$ of participants reported documenting blood loss in clinical reports, however only $47.8 \%$ of participants believed their estimation of external blood loss was accurate with $13 \%$ reporting underestimation and $33.5 \%$ reporting overestimation of blood loss. Additionally, only $51.6 \%$ of participants agreed to strongly agreed that they were confident in their estimation of blood loss.

\section{Conclusion}

This research demonstrates the majority of paramedics estimate and document external blood loss, yet nearly half do not feel confident in doing so, despite indicating its importance. Educational and organisational changes are recommended to reflect the clear evidence against this practice. Further research is recommended to identify appropriate physiological parameters and practical assessment tools to replace this inaccurate form of clinical assessment.

\section{Keywords:}

blood loss estimation; clinical decision making; emergency medical services; paramedic; pre-hospital care

Corresponding author: Wayne Harris, wayne.harris@utas.edu.au 


\section{Introduction}

Accurate estimation of external blood loss can assist in patient management, resource allocation and therefore patient outcome. Measurement of external blood loss may be done by direct measurement, visualisation, gravimetric or photometric methods (1). While gravimetric, direct measurement and photometric measurements are not without limitations, they are regarded as the most accurate (1). In the pre-hospital environment these methods are not practical due to a range of reasons such as surface type (eg. concrete, carpet, grass, vehicle interiors) and the environments in which patients may present. Visualisation therefore is the most often used assessment method for determining external blood loss in paramedic practice. Studies of the estimation of external blood loss via visualisation have been made by researchers across different disciplines and clinical contexts (2-5) including simulation studies, all of which have identified significant lack of accuracy in estimation of blood loss (2-9).

Blood loss has been found to be underestimated at high volumes and overestimated at low volumes (10). Additionally, errors in estimation are independent of clinical experience or education $(10,11)$. Under and over estimation of blood loss may result in inappropriate clinical interventions that impact patient outcome (10).

Confidence in clinical judgement can compromise the quality of care provided whether it is over- or under-confidence (12). Over-confidence, in particular, in clinical decision making has been identified as a cause of diagnostic error that leads to adverse outcomes in real world and simulated medical (13) and nursing (12) environments. Over-confident practitioners are less likely to consult with colleagues or utilise tools, protocols or practice guidelines to aid their decision making (13).

Despite findings that estimation of blood loss is inaccurate, most paramedic services within Australia continue to encourage external blood loss estimation and documentation via electronic patient care reporting mechanisms. A 2015 Queensland coroner's inquest (14) highlights ignorance around this issue. One of the recommendations of the Coroner was that the ambulance service, 'Develop procedures and training to enable ambulance officers who attend a scene and have opportunity to observe blood to more accurately record colour, consistency and volume'. In response to such recommendations, the ambulance service's medical director acknowledged the difficulties of accurate estimation of blood loss, while giving consideration to adapting reporting mechanisms regarding blood loss.

No literature has been found from 1995 to present that considers the paramedic view on the importance of recording blood loss in a patient, the degree to which the estimated blood loss informs patient management and their confidence in assessing external blood loss. The aim of this study was to determine paramedic confidence in the estimation of, and reporting of, external blood loss due to medical or trauma aetiology, within an Australasian paramedic context.

\section{Methods}

This cross-sectional study surveyed paramedics currently practising throughout Australasia. Participants were invited to complete an online survey through Survey MonkeyTM (United States) that was distributed via email to paramedic professional bodies: Paramedics Australasia (PA); and the Australia and New Zealand College of Paramedicine (ANZCP). The combined membership of PA and ANZCP is 5600 . Some members of these groups have dual membership, consequently this number may be less than stated. The invitation included a letter explaining the purpose of the study and a link to the online survey instrument. The survey was made available from July to September 2015. Participation was voluntary with anonymity maintained as no personally identifiable data was collected. Completion of the survey indicated participant consent.

The survey consisted of 27 questions including Likert scale and free text responses. Participants were asked to classify their current level of clinical practice with responses ranging from novice, intermediate and advanced skill level. The following criteria were used to group the participants: Novice paramedic - basic life support (first responder/volunteer and student paramedic); Intermediate paramedic - advanced life support (advanced care); Advanced care paramedic (intensive care, critical care, extended care). Questions also focused on the participants' years of clinical experience and work environment (urban/rural). Ten questions focused on experience in assessing external blood loss, including how often participants documented this in practice, whether it was used to inform patient management and level of importance of accurately determining external blood loss. Six questions focused on confidence in assessing external blood loss including how confident participants are in estimating external blood loss and whether they overestimate or underestimate amount.

Numbers and percentages are presented for descriptive characteristics of the cohort. Group differences were examined using chi-square tests for categorical variables. Fishers exact test was applied where $20 \%$ of cell frequencies fell below five. Explanatory variables were years of experience, level of clinical practice, previous health care training or education and rural versus urban working environment. Response variables were measures of reporting, accuracy in estimations of blood loss and confidence in estimations of blood loss. Initial analysis of the data found age to be significantly associated with most explanatory and response measures. 
Age was therefore treated as a confounder and adjusted for in the multivariable explanatory analysis. Where there was a statistically significant association the Phi statistic is reported as the measure of effect for two binary variables and Cramers $V$ for categorical variables with more than two categories. Effect sizes are interpreted as small (0.1), moderate (0.3) and strong as (0.5). SPSS (Statistical Package for the Social Sciences) version 22 was used for the analysis of quantitative data.

\section{Ethics}

Ethics approval was granted by the University of Tasmania Human Research Ethics Committee (H0015028).

\section{Results}

A total of 5600 participants were sent emails inviting them to participate in the survey. Of those, 208 responded (response rate 3.7\%). Table 1 shows the basic demographic characteristics of the cohort. All responses were from Australian paramedics.

\section{Documentation of external blood loss}

When presented with a case of external blood loss the majority of participants $86.6 \%$ (175/202) reported 'yes' that they documented the estimation of blood loss on the patient care record. Factors associated with an increased likelihood of documenting external blood loss are shown in Table 2 and include work experience and level of clinical practice. Previous healthcare training and rural versus urban location was not significantly associated with any of the documentation response variables. Age did not explain these associations in the adjusted analysis. Participants also agreed that it was important to very important to document external blood loss $(61.6 \%, 128 / 163)$ and $55.8 \%(91 / 163)$ reported that they always document the blood loss on the patient care record, $34.4 \%$ (56/163) often and 9.8\% (16/163) sometimes or rarely. When asked how often blood loss estimation was used to inform patient management $36.8 \%(60 / 163)$ reported always, $31.9 \%$ (52/163) often, $23.3 \%$ (38/163) sometimes and $8 \%(13 / 163)$ rarely or never. There were no significant associations between these response variables (importance and frequency of documentation and informed patient care) and the explanatory variables.

\section{Importance of estimation of external blood loss}

Overall 58.5\% (95/163) of participants thought it was very important or essential to estimate external blood loss in their practice, 20.2\% (33/163) thought it was important whereas $21.5 \%(35 / 163)$ reported it as somewhat or not important. The majority of participants $(59.1 \%, 123 / 163)$ agreed or strongly agreed that it was important to be able to estimate blood loss accurately in medical patients and 67.8\% (141/163) agreed or strongly agreed that it was important to estimate blood loss accurately in trauma patients. There were no significant associations between the explanatory variables and a belief in the importance of estimating external blood loss.

Table 1. Demographic characteristics of the participants

\begin{tabular}{|l|l|}
\hline \multicolumn{1}{|c|}{ Characteristic } & \multicolumn{1}{|c|}{$\mathbf{N ~ ( \% )}$} \\
\hline Age & $69(33.2)$ \\
$<30$ years & $100(48.1)$ \\
$31-45$ years & $39(18.8)$ \\
$>45$ years & \\
Current level of clinical practice\# & $58(27.9)$ \\
Novice & $120(57.7)$ \\
Intermediate & $30(14.4)$ \\
Advanced & \\
Years worked in paramedicine & $101(48.6)$ \\
$<5$ years & $107(51.4)$ \\
$\geq 5$ years & \\
Previous health education or training & $92(44.4)$ \\
Yes & \\
Representation by state* & $79(38)$ \\
New South Wales & $46(22.1)$ \\
Victoria & $40(19.2)$ \\
Queensland & $14(6.7)$ \\
Tasmania & $10(4.8)$ \\
Western Australia & $8(3.8)$ \\
Northern Territory & $3(1.4)$ \\
South Australia & $10 \mathrm{missing}$ \\
\hline
\end{tabular}

*percentages do not add up to $100 \%$ due to missing data $(n=8)$

\#Novice paramedic: basic life support (first responder or volunteer) and student paramedic; Intermediate paramedic: advanced life support (ALS) and advanced care; Advanced care paramedic: Intensive care, critical care, extended care

\section{Accuracy of estimation of external blood loss}

When participants were asked if they believed their estimates of external blood loss in the patients they attend was accurate, $47.8 \%(77 / 161)$ reported that they agreed or strongly agreed, $41.6 \%(67 / 161)$ neither agreed nor disagreed and $10.6 \%$ (17/161) disagreed or strongly disagreed. Twenty-one participants $(13.0 \%)$ agreed or strongly agreed that they believed they underestimated external blood loss, while $48.4 \%$ (78/161) neither agreed nor disagreed with this statement and $38.5 \%(62 / 161)$ agreed or strongly disagreed. Fifty-four $(33.5 \%)$ agreed or strongly agreed that they overestimate external blood loss, 42.2\% (68/161) neither agreed nor disagreed and $24.2 \%$ (39/161) disagreed or strongly disagreed that they overestimated external blood loss. Table 3 shows factors associated with paramedics' self-reported accuracy in the estimation of blood loss. 
Harris: Paramedic confidence in estimating external blood loss

Australasian Journal of Paramedicine: 2017;14(3)

Table 2. Documentation of blood loss on the patient care record

\begin{tabular}{|c|c|c|c|}
\hline & & Yes & $p$-value \\
\hline $\begin{array}{l}\text { Do you document the volu } \\
\text { record? }\end{array}$ & ur patient care & $\%$ & \\
\hline Age & $\leq 30$ years & 77.3 & $X^{2}(2, n=202)$ \\
\hline & $31-45$ years & 89.7 & $8.06, p=0.018$ \\
\hline & $>45$ years & 94.9 & \\
\hline Years of experience & $<5$ years & 75.8 & $X^{2}(1, n=202)$ \\
\hline & $\geq 5$ years & 96.3 & $18.21, p \leq 0.001$ \\
\hline Level of clinical practice\# & Novice & 71.7 & \\
\hline & Intermediate & 90.8 & $X^{2}(2, n=202)$ \\
\hline & Advanced & 96.7 & $14.56, p=0.001$ \\
\hline
\end{tabular}

\#Novice paramedic: basic life support (first responder or volunteer) and student paramedic; Intermediate paramedic: advanced life support (ALS) and advanced care; Advanced care paramedic: Intensive care, critical care, extended care

Older age, more years of work experience and a higher level of clinical practice were all significantly associated with a belief that the estimation of external blood loss was more likely to be accurate and less likely to be overestimated. Younger, less experienced paramedics were more likely to agree that they might overestimate blood loss although these associations were not significant.

Following adjustment for age there was a significant interaction between years of experience and self-perceived accuracy of blood loss estimation. Participants less than 30 years of age and with more than 4 years of experience were significantly more likely to agree or strongly agree that their estimation of external blood loss was accurate: $X 2(2, N=43)$, 7.17, $p=0.028$, with a moderate effect size $(\phi=409)$ (Figure 1). No other significant associations were found following adjustment for age for measures of accuracy of blood loss estimation and level of clinical practice, suggesting that age does not explain these associations.

\section{Confidence in estimating external blood loss}

The majority of participants $(51.6 \%, 83 / 161)$ agreed or strongly agreed that they were confident in estimating external blood loss in trauma patients, 36.6\% (39/161) neither agreed nor disagreed and $11.8 \%$ (19/161) disagreed or strongly disagreed. By comparison, 31.7\% (51/161) agreed or strongly agreed that they were confident in estimating external blood loss in medical patients, $45.3 \%$ (73/161) neither agreed nor disagreed and 23\% (37/161) disagreed or strongly disagreed. Factors significantly associated with confidence in estimating blood loss in both medical and trauma patients include clinical practice and years of experience (borderline significance for trauma patients) (Table 4). Age did not explain differences in confidence associated with years of experience or level of clinical practice. Increased confidence in estimating external blood loss in medical patients was also significantly associated with an increased belief in the accuracy of that estimation $X^{2}(4, N=161), 13.40, p=0.009$, and a tendency to disagree that they overestimate blood loss $X^{2}(4, N=161)$, $24.01, p \leq 0.001$. Similar associations were found between increased confidence in estimating blood loss in trauma patients and accuracy of blood loss $X^{2}(4, N=161), 98.60$, $p \leq 0.001$ and disagreement with overestimation of blood loss $X^{2}(4, N=161), 23.86, p \leq 0.001$.

\section{Discussion}

Several important points have emerged from this study. First, paramedics are still visually estimating external blood loss and using this estimation in clinical decision-making. Secondly, this estimate is routinely documented on patient care records supplied by ambulance services. Thirdly, confidence in the accuracy of the estimation of blood loss is increased in those practitioners with greater years of service, clinical experience and clinical qualifications.

Gravimetric, volumetric, and photometric measurements of blood loss (while the most accurate) are not feasible, in most situations, in pre-hospital environments. Previous studies have clearly identified significant limitations in visual estimation of blood loss in various health professions both in clinical practice and simulated environments (1-5,8-10). Despite this clear evidence, our study has shown that visual estimation of blood loss is still commonly used in paramedic practice within Australia. 
Table 3. Reported belief in accuracy of estimation of external blood loss and associations with explanatory variables

\begin{tabular}{|c|c|c|c|c|c|}
\hline \multicolumn{2}{|c|}{$\begin{array}{l}\text { I believe the estimation of actual external blood loss } \\
\text { is ACCURATE in the patients I attend }\end{array}$} & $\begin{array}{l}\text { Agree to } \\
\text { strongly agree }\end{array}$ & $\begin{array}{l}\text { Neither agree } \\
\text { or disagree }\end{array}$ & $\begin{array}{l}\text { Disagree to } \\
\text { strongly disagree }\end{array}$ & $p$-value \\
\hline \multirow{4}{*}{ Age } & & & & & \\
\hline & $\leq 30$ years & 25.6 & 58.1 & 16.3 & $X^{2}(4, N=161)$ \\
\hline & $31-45$ years & 52.4 & 40.2 & 7.3 & $14.16, p=0.007$ \\
\hline & $>45$ years & 63.9 & 25.0 & 11.1 & \\
\hline \multirow[t]{2}{*}{ Years of experience } & $<5$ years & 34.4 & 54.7 & 10.9 & $X^{2}(2, N=161)$ \\
\hline & $\geq 5$ years & 56.7 & 33.0 & 10.3 & $8.39, p=0.015$ \\
\hline \multirow[t]{3}{*}{ Level of clinical practice\# } & Novice & 22.6 & 58.1 & 19.4 & $X^{2}(4, N=161)$ \\
\hline & Intermediate & 54.4 & 38.8 & 6.8 & $11.91, p=0.018$ \\
\hline & Advanced & 51.9 & 33.3 & 14.8 & \\
\hline \multirow[t]{2}{*}{$\begin{array}{l}\text { I believe I OVERESTIMATE } \\
\text { external blood loss }\end{array}$} & & $\begin{array}{c}\text { Agree to } \\
\text { strongly agree }\end{array}$ & $\begin{array}{l}\text { Neither agree } \\
\text { or disagree }\end{array}$ & $\begin{array}{c}\text { Disagree to } \\
\text { strongly disagree } \\
\end{array}$ & $p$-value \\
\hline & & $\%$ & $\%$ & $\%$ & \\
\hline \multirow[t]{3}{*}{ Age } & $\leq 30$ years & 53.5 & 27.9 & 18.6 & $X^{2}(4, N=161)$ \\
\hline & $31-45$ years & 28.0 & 47.6 & 24.4 & $11.22, p=0.024$ \\
\hline & $>45$ years & 22.2 & 47.2 & 30.6 & \\
\hline \multirow[t]{2}{*}{ Years of experience } & $<5$ years & 46.9 & 31.3 & 21.9 & $X^{2}(2, N=161)$ \\
\hline & $\geq 5$ years & 24.7 & 49.5 & 25.8 & $8.90, p=0.012$ \\
\hline \multirow[t]{3}{*}{ Level of clinical practice\# } & Novice & 54.8 & 35.5 & 9.7 & $X^{2}(4, N=161)$ \\
\hline & Intermediate & 27.2 & 42.7 & 30.1 & $10.53, p=0.032$ \\
\hline & Advanced & 33.3 & 48.1 & 18.5 & \\
\hline \multirow[t]{2}{*}{$\begin{array}{l}\text { I believe I UNDERESTIMATE } \\
\text { external blood loss }\end{array}$} & & $\begin{array}{c}\text { Agree to } \\
\text { strongly agree }\end{array}$ & $\begin{array}{l}\text { Neither agree } \\
\text { or disagree }\end{array}$ & $\begin{array}{c}\text { Disagree to } \\
\text { strongly disagree } \\
\end{array}$ & $p$-value \\
\hline & & $\%$ & $\%$ & $\%$ & \\
\hline \multirow[t]{3}{*}{ Age } & $\leq 30$ years & 18.6 & 39.5 & 41.9 & $X^{2}(4, N=161)$ \\
\hline & $31-45$ years & 11.0 & 51.2 & 37.8 & $2.55, p=0.635$ \\
\hline & $>45$ years & 11.1 & 52.8 & 36.1 & \\
\hline \multirow[t]{2}{*}{ Years of experience } & $<5$ years & 12.5 & 43.8 & 43.8 & $X^{2}(2, N=161)$ \\
\hline & $\geq 5$ years & 13.4 & 51.5 & 35.1 & $1.26, p=0.531$ \\
\hline \multirow[t]{3}{*}{ Level of clinical practice\# } & Novice & 19.4 & 54.8 & 25.8 & $X^{2}(4, N=161)$ \\
\hline & Intermediate & 12.6 & 46.6 & 40.8 & $3.64, p=0.457$ \\
\hline & Advanced & 7.4 & 48.1 & 44.4 & \\
\hline
\end{tabular}

\#Novice paramedic: basic life support (first responder or volunteer) and student paramedic; Intermediate paramedic: advanced life support (ALS) and advanced care; Advanced care paramedic: Intensive care, critical care, extended care 
Table 4. Reported confidence in estimation of external blood loss and associations with explanatory variables

\begin{tabular}{|c|c|c|c|c|c|}
\hline \multicolumn{2}{|c|}{$\begin{array}{l}\text { I am CONFIDENT in estimating external blood loss } \\
\text { in MEDICAL patients }\end{array}$} & \multirow{2}{*}{$\begin{array}{c}\begin{array}{c}\text { Agree to } \\
\text { strongly agree }\end{array} \\
\% \\
11.6\end{array}$} & \multirow{2}{*}{$\begin{array}{c}\begin{array}{c}\text { Neither agree } \\
\text { or disagree }\end{array} \\
\% \\
65.1\end{array}$} & \multirow{2}{*}{\begin{tabular}{|c}
$\begin{array}{c}\text { Disagree to } \\
\text { strongly disagree }\end{array}$ \\
$\%$ \\
23.3
\end{tabular}} & \multirow{2}{*}{$\begin{array}{c}\text { p-value } \\
X^{2}(4, N=161),\end{array}$} \\
\hline Age & $\leq 30$ years & & & & \\
\hline & $31-45$ years & 36.6 & 42.7 & 20.7 & $14.76, p=0.005$ \\
\hline & $>45$ years & 44.4 & 27.8 & 27.8 & \\
\hline \multirow[t]{2}{*}{ Years of experience } & $<5$ years & 20.3 & 54.7 & 25.0 & $X^{2}(2, N=161)$ \\
\hline & $\geq 5$ years & 39.2 & 39.2 & 21.6 & 6.56. $p=0.038$ \\
\hline \multirow[t]{3}{*}{ Level of clinical practice\# } & Novice & 6.5 & 67.7 & 25.8 & $X^{2}(4, N=161)$ \\
\hline & Intermediate & 39.8 & 40.8 & 19.4 & $14.66 p=0.005$ \\
\hline & Advanced & 29.6 & 37.0 & 33.3 & \\
\hline \multirow{2}{*}{$\begin{array}{l}\text { I am CONFIDENT in estimat- } \\
\text { ing external blood loss in } \\
\text { TRAUMA patients }\end{array}$} & & $\begin{array}{c}\text { Agree to } \\
\text { strongly agree }\end{array}$ & $\begin{array}{l}\text { Neither agree } \\
\text { or disagree }\end{array}$ & $\begin{array}{c}\text { Disagree to } \\
\text { strongly disagree }\end{array}$ & $p$-value \\
\hline & & $\%$ & $\%$ & $\%$ & \\
\hline \multirow[t]{3}{*}{ Age } & $\leq 30$ years & 27.9 & 51.2 & 29.9 & $X^{2}(4, N=161)$ \\
\hline & $31-45$ years & 59.8 & 34.1 & 6.1 & 15.74. $p=0.003$ \\
\hline & $>45$ years & 61.1 & 25.0 & 13.9 & \\
\hline \multirow[t]{2}{*}{ Years of experience } & $<5$ years & 40.6 & 43.8 & 15.6 & $X^{2}(2, N=161)$ \\
\hline & $\geq 5$ years & 58.8 & 32.0 & 9.3 & 5.24. $p=0.073$ \\
\hline \multirow[t]{3}{*}{ Level of clinical practice\# } & Novice & 12.9 & 61.3 & 25.8 & $X^{2}(4, N=161)$ \\
\hline & Intermediate & 62.1 & 31.1 & 6.8 & 25.22. $p \leq 0.001$ \\
\hline & Advanced & 55.6 & 29.6 & 14.8 & \\
\hline
\end{tabular}

\#Novice paramedic: basic life support (first responder or volunteer) and student paramedic; Intermediate paramedic: advanced life support (ALS) and advanced care; Advanced care paramedic: Intensive care, critical care, extended care

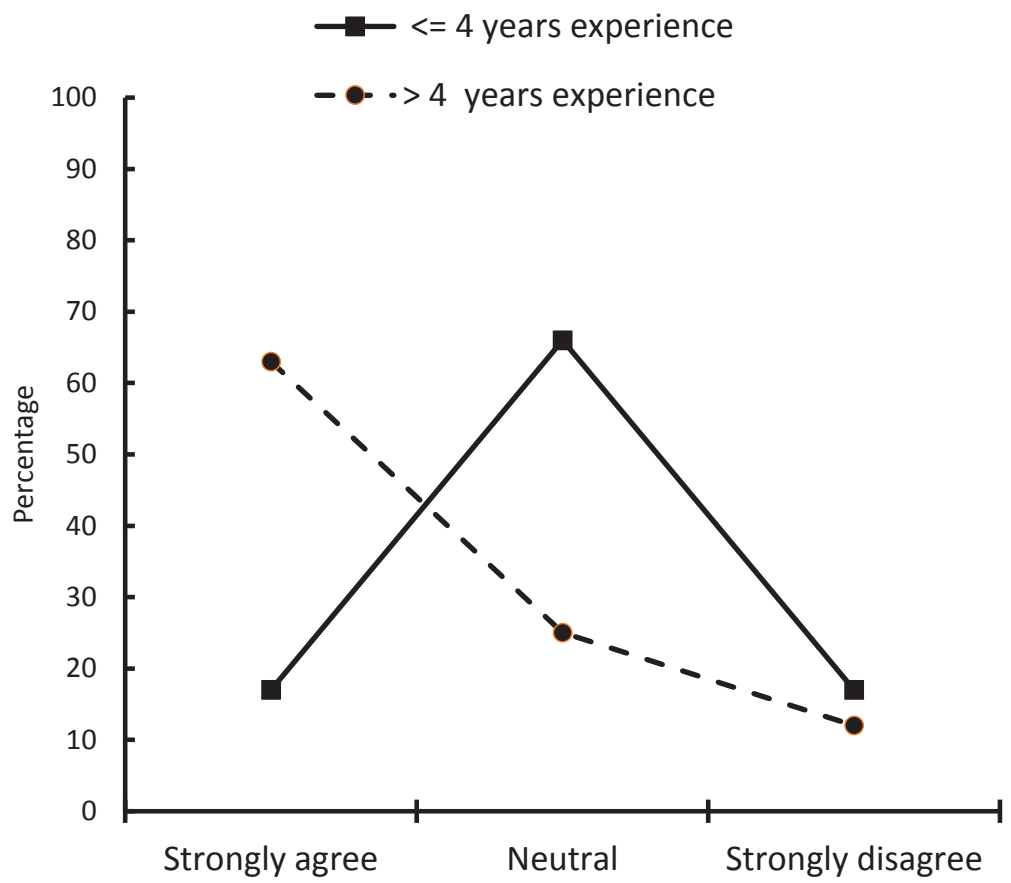

Figure 1. Participant's belief in the accuracy of external blood loss in those less than 30 years of age according to years of experience 
Irrespective of physiological signs, the majority of participants believed estimation of blood loss is important in clinical decision-making and should be documented. Interestingly, the majority of participants believe accuracy in estimating blood loss is more important in trauma patients, compared to medical patients. This study did not clarify why this occurs. It does however raise questions regarding paramedic educational processes, perceptions and confidence around medical and trauma cases in general.

Ambulance services throughout Australia tacitly encourage reporting of blood loss via electronic patient care record systems by providing discrete fields for blood loss. The reporting process would appear to organisationally support the notion that documenting estimation of blood loss is considered as value adding to the clinical decision making process at an organisational level. Given the high levels of error in accurate estimation of blood loss found in previous studies (2-9), this is a concern. It could be argued that basing clinical intervention on estimation of blood loss may result in over or under infusion of resuscitative fluids, other drugs, as well as incorrect resource allocation. The possible outcomes may have physiological implications for patients and financial and resourcing implications for health care providers.

\section{Overconfidence associated with greater experience and}

clinical practice level has been identified in other studies and is cause for concern. The findings in this study are reflected in general nursing (12) and medical (13) professions. As years of experience and clinical practice level increase, paramedics appear to become more confident in their estimation of their accuracy of blood loss. This data suggests that this occurs at about 5 years of paramedic service and may be a feature of generally increasing confidence in the work environment. It also correlates to the timeframe when intermediate level practitioners often seek further clinical advancement, which may indicate that their knowledge and confidence is growing. Research has shown that clinical experience does not increase accuracy in blood loss determination (9), therefore, increased confidence in these situations may lead to an overreliance on blood loss estimation over other physiological findings.

Novice practitioners and paramedics under 30 years of age indicated an ambivalent response to confidence in estimation in both medical and trauma situations. It could be argued that less experienced paramedics are less confident because they are more aware of the literature (due to recent tertiary studies) or they have not yet developed a perceived experiential base, or bias on which to draw conclusions about estimation of blood loss.

The evidence gathered suggests estimation and documentation of blood loss is widely practised, and even taught by paramedic educational providers. It is unknown if paramedics are engaging with current literature on this topic or if local work practices and protocols don't incorporate research findings.

\section{Limitations and implications}

The survey was distributed through two professional paramedic bodies, encompassing members from Australasia. A major limitation of this study is the low response rate suggesting the potential for some response bias. Caution is therefore warranted in generalising these findings to all paramedics. Low response rates to online surveys are a recognised issue for health researchers (15). Membership to the professional bodies is likely to be representative of the general population of paramedics, however, this may not be representative of those who responded to the survey. If the responders were more likely to be those participants who routinely document blood loss, then the results might be biased in overestimating these results. Even considering this potential bias, there is still sufficient concern that estimation of blood loss continues to occur and influence treatment decision making in this small sample of paramedics. Another limitation of this study is the potential for reporting bias that is inherent with the use of selfreport questionnaires. Inaccuracies in reporting may occur due to participants' desire to appear that they are performing best practice.

\section{Conclusion}

Our study adds to previous research regarding the difficulties of accurately estimating external blood loss, by adding to understanding of the confidence of paramedics to visually estimate blood loss in practice. In light of clear and compelling evidence, over some 20 years, educational providers and ambulance services are advised to revisit their teaching, policies, procedures and reporting mechanisms related to estimation of blood loss. Regardless of our study's limitations it can be argued that the practice of visually estimating and documenting blood loss, even if it is continuing in a small proportion of paramedics, is not appropriate. As participants viewed external blood loss between trauma and medical cases differently, this may prove a useful starting point for future research into paramedic attitudes and confidence contrasting medical and trauma presentations.

Misplaced confidence and lack of accuracy in visual estimation of blood loss has potential for detrimental patient outcomes. Physiological parameters and other physiological assessment tools could offer greater benefit in assessment of the patient with acute external blood loss from either medical or trauma aetiology. Further pre-hospital research is warranted, to identify appropriate and quantifiable physiological parameters and practical assessment tools that offer clear benefit in assessment of the patient with acute external blood loss from either medical or trauma aetiology. 


\section{Conflict of interest}

The authors declare they have no competing interests. Each author of this paper has completed the ICMJE conflict of interest statement.

\section{References}

1. Schorn MN. Measurement of Blood Loss: Review of the Literature. J Midwifery Womens Health 2010;55:20-7.

2. Adkins AR, Lee D, Woody DJ, White Jr WA. Accuracy of blood loss estimations among anesthesia providers. AANA J 2014;82:300-6.

3. Akhlaghi F, Jamali J. Visual estimation of post partum hemorrhage and its treatment. Tehran University of Medical Sciences 2012;70(4).

4. Beer HL, Duvvi S, Webb CJ, Tandon S. Blood loss estimation in epistaxis scenarios. J Laryngol Otol 2005;119:16-8.

5. De La Peña Silva AJ, Delgado RP, Barreto IY, De La Peña Martínez M. Is visual estimation useful in determining the extent of perioperative haemorrhage? A study of correlation among anaesthetists of intermediate and high complexity hospitals in Cartagena, Colombia. Revista Colombiana de Anestesiologia 2014;42:247-54.

6. Kreutziger J, Haim A, Jonsson K, Wenzel V, Stark M, Nussbaumer W. Variation in size of blood puddles on different surfaces. Eur J Emerg Med 2014;21:360-3.

7. Merlin MA, Alter SM, Raffel B, Pryor li PW. External blood loss estimation using the MAR Method. Am J Emerg Med 2009;27:1085-90.

8. Patton K, Funk DL, McErlean M, Bartfield JM. Accuracy of estimation of external blood loss by EMS personnel. J Trauma 2001:50:914-6.

9. Williams B, Boyle M. Estimation of external blood loss by paramedics: Is there any point? Prehosp Disaster Med 2007;22:502-6.

10. Dildy lii GA, Paine AR, George NC, Velasco C. Estimating blood loss: Can teaching significantly improve visual estimation? Obstet Gynecol 2004;104:601-6.

11. Yoong W, Karavolos S, Damodaram M, et al. Observer accuracy and reproducibility of visual estimation of blood loss in obstetrics: How accurate and consistent are healthcare professionals? Arch Gynecol Obstet 2010;281:207-13.

12. Yang $H$, Thompson $C$, Bland $M$. The effect of clinical experience, judgment task difficulty and time pressure on nurses' confidence calibration in a high fidelity clinical simulation. BMC Med Inform Dec Mak 2012;12:113.

13. Berner ES, Graber ML. Overconfidence as a cause of diagnostic error in medicine. Am J Med 2008;121(5 SUPPL.):S2-23.

14. Office of the State Coroner. Inquest into the death of Summer Alice Steer Brisbane: Queensland Government; 2015. Available at: www.courts.qld.gov.au/_data/assets/ pdf_file/0004/444289/cif-steer-sa-20151103.pdf [Accessed 14 June 2016.

15. Cho YI, Johnson TP, VanGeest JB. Enhancing surveys of health care professionals: a meta-analysis of techniques to improve response. Eval Health Prof 2013;36:382-407. 